\title{
Guilt, Suffering and Responsibility
}

\section{SHARON TODD}

This paper examines the moral significance of guilt in the context of how students confront the suffering of another. Within social-justice education, such confrontations are often staged in pedagogical efforts to encourage students to assume social responsibility. Frequently, however, the guilt that students claim to endure as a result of these pedagogical encounters is not perceived to be of much ethical import. By exploring the psychoanalytic work of Melanie Klein and the ethical philosophy of Emmanuel Levinas, this essay argues that guilt arises out of our susceptibility to another's pain and that it plays a crucial role both in 'making reparation' (Klein) and in the very formation of responsibility itself (Levinas).

It is not so unusual for teachers - such as myself - to bring stories of suffering (for example, newspaper articles on homelessness; accounts of institutional racism; biographical material on the Holocaust) into the classroom for their pedagogical value in order to animate more complex understandings of social responsibility. But by virtue of such a desire indeed demand - to touch another's life in this way, such pedagogical strategies and the responses they incite require careful consideration in terms not only of what it is we hope to do but of the actual effects of our educational encounters. Admittedly, the responses to stories of suffering can be as varied as the students who listen to them; however, I wish to focus on guilt here because it is a response whose frequency is met with apprehension and even hostility on the part of educators. Unlike empathy, for example, guilt is a response that is seen to represent a pedagogical failure of sorts, for guilt is not generally held to be morally or politically productive, and certainly is not viewed as having much educational value. ${ }^{1}$

What I am particularly interested in exploring here are two questions that open up a possibility for considering guilt as having pedagogical and ethical significance. First, what makes us susceptible to guilt in listening to stories of suffering in the first place? That is, why is guilt such a common response to being exposed to another's suffering? Second, how might we think about responsibility — both teachers' and students' - in light of such susceptibility and guilt? For instance, to what degree do students' guilty responses provoke a sense of responsibility 
toward people who suffer, and what responsibilities do educators have in the context of these student expressions of guilt? By way of response, I offer a close reading of two views of guilt, both of which speak directly to its ethical significance in the context of how each one of us engages with suffering that is not our own. Melanie Klein's psychoanalytic work focuses on the role our earliest feelings of love and aggression play in guilt, and views guilt as a necessary feature of the moral work of making reparation. Klein's thinking reminds us that this moral work is a psychical event, rooted in a particular set of relations arising from our empirical past that have an impact on how we encounter suffering in our classrooms in the present. Emmanuel Levinas's philosophical writing concerns itself less with an empirical past and more with considering how our 'pre-originary' openness to the other gestures ethically towards an unknowable future. Levinas draws attention to the metaphysical aspects of guilt and susceptibility and to how these give rise to an inevitable responsibility. Levinas's work allows us to read our classroom encounters with suffering as a possible formation of responsibility. Although there is a definite theoretical incommensurability between the two views under study, particularly insofar as one refuses the very thematisation of the subject that the other embraces, ${ }^{2} \mathrm{I}$ am reading them here in tension with each other so as to frame our attention to guilt as a complex ethical formation that both involves the subject inescapably in a psychical history and has metaphysical implications.

My choice of Levinas and Klein in particular has to do with what they have to offer a rethinking of guilt in education based on a number of assumptions they share. Both view affect as significant not only to learning but to engagements with difference. Both, moreover, view the fragility of the self as the source of traumatic wounding when it encounters difference, when there is acknowledgement that the other disrupts one's self-identity. And, finally, both view the relation between self and other as basically non-reciprocal and asymmetrical. As Noreen O'Connor writes of the more general affinities between psychoanalysis and Levinasian philosophy:

Psychoanalysis highlights the fact that the time of each human being is not the time articulated by historiographers; rather, it is constituted by the individual's relationships to other people. What is at issue is the difference yet relationship between people, separation and individuation ... . Without elaborating a model of genetic development of the psyche in terms of a drive economy, Levinas nevertheless also concentrates on the separation and yet the vulnerability of the 'self' (O'Connor, 1991, p. 229).

Despite such similarities, however, I do not wish to dissolve the tensions between Levinas and Klein. In fact, my purpose here is to explore the different stakes in guilt as something that both contains traces of the past in the present (Klein) and conditions the possibility for a responsible subjectivity (Levinas). In this regard I am not trying to 
integrate these two views theoretically, but to work within and through their very differences.

\section{GUILT AS A PEDAgOGICAL PROBLEM}

There are many ways in which guilt structures students' response to what Levinas refers to as the 'uselessness' of suffering, that is, the inherent purposelessness of another's suffering. When students confront such suffering, they frequently invoke various types of guilty responses. For my purposes here, I wish to sketch out three types of declarations in order to highlight the avenues through which guilt enters pedagogical discourse. They are presented here less as a typology than as a set of discursive constructs that frequently overlap and are often expressed by the same person. The methodological risk, of course, is that the complexity of guilt as a phenomenon is reduced to these types. I recognise that guilt can take many forms, and expressions of it range across a wide array of behaviours. However, my point is to examine possible ways in which students identify themselves as guilty subjects. Using these three types heuristically allows us to consider the multivalent nature of guilt itself and tentatively to identify what might be ethically significant about claiming guilt.

First, students make claims about feeling responsibility for deeds they have not committed and despair because they believe they have not done enough to help out those who suffer. Students who make such utterances inhabit a position in which recognition of the suffering of another brings with it a commensurate (if not equal) suffering to them. That is, their guilt is a kind of punishment directed toward themselves, for they feel they cannot act — or have not acted — in such a way as to prevent or ameliorate such harm. For instance, in confronting the issue of homelessness, students might reprimand themselves for not being able 'to do enough', and struggle to articulate what it is that can in fact be done. What is often obvious in these situations is the sense of remorse that sets in in the face of another's pain, not because one actually has been involved directly in causing that pain, but because an involvement of the self is nonetheless called into being in confronting it. ${ }^{3}$

Second, there are cases where students' feelings of being overwhelmed by another's suffering compel them to call into question their own privilege. Awakening to the harshness of others' experiences of the world, they feel guilty because they have not 'suffered enough'. A hierarchy of oppression and suffering emerges in their understanding of the other. This position does not concentrate on what can or ought to have been done to prevent or remedy the injustice. Rather, it centres the ego as the site of the problem. In some ways various pedagogies encourage the taking up of this position for the very reason that it is precisely in the act of undoing one's privilege that one is supposedly then able to assume responsibility. The focus on one's own lack of suffering (for that is how privilege is defined in such declarations) reflects a type of survivor guilt whereby one's ego is called into question for having been 
spared the indignities (and, in confronting certain stories of genocide, perhaps even death) to which the other has been subjected.

Third, some students claim that they are being made to feel guilty, underscoring the idea that they are not responsible at all because they have not directly caused any harm. Here, then, there is no sense of remorse present, nor is there a centring of the ego's privilege and lack of suffering; instead there appears to be a powerful attempt to squirm out, seemingly unscathed, from underneath the oppressive weight of their new knowledge of another's suffering. The focus is on how they are not responsible for past injustices, that they personally have done nothing wrong and therefore have nothing to atone for - and it is assumed (often quite rightly) that this is indeed what the teacher is demanding. Their declarations of innocence appear less like guilt and more like externalised anger - the trajectory of which often effectively disrupts the teacher's pedagogical intentions. Although one could easily argue that such a position is really not about guilt at all, but more about resistance,${ }^{4}$ what remains more interesting for my purposes here are the curious ways in which these students, by proclaiming their guilt (and apparent innocence), also affirm that some wrong has been committed. That is, their act of speech betrays that which they cannot directly speak: another's pain. In identifying guilt as significant in listening to stories of suffering, these students' speech, as in the examples above, also recognises that something wrongful has occurred, even as they underscore their own personal distance from it. In fact, it is precisely their need to declare their distance that indicates to me that there is a far deeper, if tacit, realisation that there is indeed something from which they want to distance themselves.

What is put into sharp relief in each of these very different pronouncements is the pre-eminence of guilt as a pedagogical force to be reckoned with, where learning about another's pain becomes refracted through one's declared sense of responsibility (or lack thereof). What such responses suggest about guilt is that it signals to the self, in the moment of articulation, that one is implicated in a wrong committed against another. Unlike shame, for example, which focuses on how the self is perceived by the self in relation to an event that might not even involve the suffering of another (for example, one can feel shame for behaving or thinking in a certain manner even when no other person was the object of those actions or thoughts), these assertions of guilt, on the other hand, assume a social responsibility, where another's well-being is always at risk. ${ }^{5}$ Hence arises the need to self-declare that one is or is not responsible, often either to reassure oneself that one is as good as one thinks, or to persuade others of the same; and this responsibility is invoked, as we shall see below, because it is precisely responsibility that is at stake in guilt. Guilt connects the self to the external world, to the realm of the social, while shame remains confined within the self's parameters of self-idealisation. Guilt, in this sense, although obviously concerned with how the self is perceived, is more closely tied to how the self is perceived in terms of the quality of relationships with others. If 
one were simply to feel shame (and I do not mean to imply that shame is ever that simple), then it is not clear that one would feel some responsibility for another; it would merely indicate that one holds oneself in severe disregard; shame often involves something that one cannot bring oneself to articulate to another.

Could it be that these responses are merely misrecognitions of guilt? It is not so much whether students have identified their feelings 'accurately' or 'correctly' according to some prior and stable definition of guilt; instead, it is the very movement of self-identifying as a guilty subject, and how this movement is such a commonplace response to stories of suffering, that calls for some unpacking. In this regard, I am interested in why guilt gets identified so readily, how these self-declarations actually do speak to a guilt that arises out of a susceptibility to the other, ${ }^{6}$ and how this carries profound ethical significance. It is important too to ask ourselves how educators handle these movements of selfidentification, these utterances of guilt, and the acts of uttering them, given that it is our very pedagogies that make possible such declarations in the first place. ${ }^{7}$ In turning to a close reading of the work of Klein and Levinas I hope to offer some navigational tools by which we might consider guilt as fundamental to the process of making reparation and to the formation of responsibility; I hope also to offer some observations as to how and why this is significant for education.

\section{'LOVE, GUILT AND REPARATION'}

In her key work on guilt, 'Love, Guilt and Reparation' from 1937, Klein offers a developmental account of the emergence of guilt from infancy onward. Despite its rather literal emphasis on family stereotypes, this text works to articulate the ways in which early infantile and childhood experiences profoundly affect the emotional and psychical landscape of the adult. In this rather lengthy and complex essay, Klein begins with the significance of aggression in constituting guilty feelings but is fundamentally concerned 'to give a picture of the equally powerful force of love and the drive to reparation' (Klein, 1992, p. 306). Thus what we have from the start is a text that seeks to detail the ambivalence that lies at the core of what Zygmunt Bauman refers to as the 'moral impulse' (Bauman, 1993, esp. pp. 10-13).

Klein's schema relies upon her work with children in analysis - work which has led her to posit that early formations of subjectivity are inherently violent as much as they are inherently innocent and full of love. An infant, according to Klein, lives through this ambivalence by directing toward the one she is most bound to in love various physical acts of rejection (for example, biting, kicking, pushing away). More importantly for Klein, however, are the early fantasy formations that occur alongside both the aggression and the love that the infant has for the care-giver (that is, the mother) to the point that aggressive fantasies themselves (not the actual acts of aggression) give rise to intense feelings of anxiety. ${ }^{8}$ According to Klein, 'A most important feature of these 
destructive phantasies, which are tantamount to death wishes, is that the baby feels that what he desires in his phantasies has really taken place; that is to say he feels that he has really destroyed the object of his destructive impulses' (p.308). Moreover, in providing a figure of subjectivity that is tied to one's early relations with others, Klein suggests that guilt is itself an inevitable and important part of one's development. More surprising perhaps - and this is key, I believe, to Klein's understanding of reparation - is her assertion that guilt is also involved in the subject's capacity for love. She writes:

My psychoanalytic work has convinced me that when in the baby's mind the conflicts between love and hate arise, and the fears of losing the loved one become active, a very important step is made in development. These feelings of guilt and distress now enter as a new element into the emotion of love. They become an inherent part of love, and influence it profoundly both in quality and quantity (p.311, emphasis added).

What Klein is suggesting here is that guilt, even as it is an expression of the death drive, is part of the very landscape of love, and that consequently such love bears traces of the death and destruction wrought by fantastical representations of the loved one. Guilt and love, although emotionally distinct, are nonetheless inextricably linked through the complicated and ambivalent ties that bind us to other people and the fears we have about losing them. Indeed, it is, according to Klein (who follows Freud here), the fear of losing love that initially arouses guilt and the subsequent (albeit nascent) awareness that one loves the other; consequently, the subject must protect the injured other from the violence of the self. It is in this sense, then, that guilt begins to participate in feelings of love insofar as this love carries with it an insecurity borne out of an impulse to destroy.

In being alloyed to love, guilt provokes a desire to repair the damage suffered by the loved one. That is, the subject seeks to make amends, to restore and repair the injured party through yet another layer of fantasy. But does this occur in order for one to remain loved (in order to master the fear of loss of love) or is it to keep one's love of the other intact (because one finds doing harm to the loved one intolerable)? What exactly leads to such reparative and restorative impulses?

There are no simple answers to this in Klein's account. At times Klein asserts that love for the mother gives rise to guilt and the reparative impulse; yet we have seen she also declares that guilt is a fundamental part of love itself, suggesting that love is already tinged with guilty affect. On other occasions, it is the sheer fear of loss of love and the fear of one's own aggression in contributing to this loss that is highlighted. At other times, she announces that reparation is central to love relations, rather than the other way around, seeming to indicate that reparation lies in a prior relation to love. ${ }^{9}$ At yet other times, Klein asserts that reparation is of the order of a 'drive', which in psychoanalytic terms signifies an impulse whose existence lies internally within the subject. ${ }^{10}$ 
Despite the confusion over the precise sequencing of love, guilt, and reparation, Klein's text continually reiterates the point that it is the presence of both love and guilt that is necessary for forming moral relationships with others. Ironically, perhaps, given the Kleinian emphasis on the power of aggressive fantasies and the account of the dreadful capacity for destruction human beings have, guilt nonetheless occupies a position that is, as Judith Butler would say, 'strangely innocent' ${ }^{11}$ That is, it is characteristic of an initial susceptibility to another's presence and lies in a prior relation to any assumption of the law or language or identity. The subject's capacity for guilt, according to Klein, occurs in a pre-Oedipal moment (to use Freudian terminology) where it is the nascent awareness of another's suffering and the part one plays in it - rather than knowledge of right and wrong - that is firmly at issue. What Klein's work implicitly traces is how we come to care about the suffering of another and how this leads to a development of one's moral sensibilities. And Klein postulates that, growing out of this initial love attachment to the mother, we transfer onto others our 'interest and love', and hence our capacity for 'making reparation ... widens in scope' (p.342). It is because we feel love and cause pain simultaneously that we experience guilt. Although we can only perhaps feel guilt if we are capable of love, so too can we only make good harm done to another if we are capable of guilt.

Fantasies of aggression as well as love can be seen to be at work in students' declarations of guilt, even for deeds they have not committed. How one imagines another's suffering - and how one imagines oneself in relation to that suffering - permeates and frames such declarations. In considering the three articulations of guilt mentioned above, one can see that in each case students reveal where they imagine themselves to be situated in relation to the harm they have witnessed, and thus speak to the way they perceive themselves to be both potential injurers and potential repairers. Each position reveals several possible reversals of meaning, where the absent presence of the utterance, or what remains unspoken, lies in the twinning of love and aggression that marks the students' entry into guilt.

The first position regarding the despair of not being able to do enough about an unjust situation (such as homelessness, for example) reveals two implicit messages. On the one hand, in voicing worry and concern that one has not done enough to alleviate suffering the idea is simultaneously conveyed 'if I don't do enough I am harming the other'. Here we see how one's own concern about the other's suffering implicates the self in causing harm and rests on one's imagined presumption that one has indeed caused harm to another. This is not to say that there is no external truth to this statement; certainly the failure to take action definitely can lead to causing or furthering actual harm. Nonetheless, what remains important is that one's imagined role in the life of another's suffering is also connected to one's imaginative reconstructions of the capacity to cause harm, in spite of any external factors. On the other hand, there is also an opposite trajectory at play in 
one's concerns over doing enough, for implied here is yet another meaning: 'if I do do something I can ameliorate another's suffering'. Thus there is an imagined reparative tendency embedded within the very concern with the other's pain or misery. In this respect, to claim that one may not have done enough may also be opening up the possibility for recognising that there is something to do.

As for the second example, the claim focuses on one's own lack of suffering in the face of another's pain. Here we see a similar, though different kind of pattern.

Students read their own privilege as the very marker of someone else's injury: thus 'my privilege has caused someone else hardship'. Here, too, the statement contains an imaginary element that one has caused suffering, this time through one's relative difference to the other. There is a tacit recognition of aggression here, insofar as one's privilege is the basis of pain for someone else. However, the tendency to reparation is not so straightforward as in the first example, and often takes one of two directions: either one can undo one's privilege in order to relieve the suffering which that privilege has caused, or, in an attempt to reverse the equation 'lack of suffering=harm to another', one can seek to suffer equally alongside the other. Thus in this position it is essentially the centring of the ego as a privileged site which suggests that the reparative or moral response needs to be seen in terms of 'undoing' privilege rather than 'obtaining' equal suffering.

The third type of utterance concerns the need to distance oneself from the suffering of another altogether. Here, too, we see the capacity for aggression and reparation internal to such statements. Aside from the anger, the insistence on distance can also be understood as an admission of aggression toward the one who has suffered. That is to say, one of the meanings underlying this distance is that 'if I don't distance myself, I am the oppressor'. Guilt in this scenario carries with it the devastating idea that one has the potential to harm others without intention, and that this idea is itself too painful to bear. As for its reparative tendencies, distancing oneself, and therefore declaring one's innocence, not only means that one has attempted to wash one's hands of the suffering, thereby denying any involvement in that pain; it also entails that distance embeds within it another meaning: 'by distancing myself I am not harming you any more'. For unlike statements of outright hate for a group, or of blaming people for their own suffering, this kind of declaration of guilt underscores a profound ambivalence about one's own ambivalent relation to the other. That is to say, it is precisely in the moment of becoming aware of the other's suffering that one confronts one's own aggression and love from which one has to distance oneself. In this sense, the distancing is not just about creating a space between self and other, but about effectively distancing the self from itself from its own affective response.

The hope that Kleinian reparation offers is constructive for escaping the straitjacket view of guilt that claims it is either morally insignificant or politically noxious. ${ }^{2}$ In explaining the psychical dynamics of how 
guilt incites moral action, Klein's work is especially fertile. She enables us to reflect upon the dynamics at stake in various positions of guilt and the kinds of fantasies of aggression and reparation that subtend them. As Klein suggests, such capacities for aggression and reparation stem from an initial alloying of guilt with love in our early relationships. Thus for Klein, as for psychoanalysis in general, the psychical past cuts into the present, giving the subject a history that continually shapes our relations to others. It is a history, moreover, without which we are, I believe, theoretically impoverished when it comes to considering the delicacy and complexity of human relationality across difference, and the difficulties that arise as a result.

However, the notion of reparation still cannot fully explain the state of responsibility in responding to stories of suffering. By this I mean to suggest that while fantasy plays a pivotal role in theorising psychical investments in self-identifying as feeling guilty (especially those feelings for deeds we have not committed), what it cannot accomplish fully on its own is the constitution of responsibility in relation to guilt. That is, the drive or impulse to 'make good' the harms done to another is accounted for through an empirical set of concerns over how we may come to develop a moral impulse. That is, reparation is always already constituted within the given frames of reference of the other as a psychical subject, understood through psychoanalytic discourse. And while this subject may not 'be like me' in its idiosyncratic detail, how we understand it is nonetheless subjected to a thematisation that applies to both of us, that, as it were, catches us both in the same ontological net. ${ }^{13}$

Levinas's view of responsibility, while certainly tied to its own philosophical tradition, nonetheless attempts to put into question the very nature of the subject and theorises responsibility not as something that lies 'within' the subject but as something that comes to the subject from the other. That is, responsibility avoids the thematisation of the subject which reparation necessarily relies upon. While reparation speaks to the moral capacity of the individual as an empirical subject, responsibility refers to the inevitable ethical condition that makes each one of us subjects in the first place. For Levinas, subjectivity itself is radically constituted as responsibility. As Alphonso Lingis succinctly puts it, 'For Levinas responsibility is in the response to the imperative addressed in the concrete act of facing. Responsibility is in fact a relationship with the other, in his very alterity. Then a relationship with alterity as such is constitutive of subjectivity' (Lingis in Levinas, 1998a, p. xix). What this means for guilt, as we shall see, is that not only is it a psychical response to the specificity of another's suffering: it is also a condition of the susceptibility to another that constitutes subjectivity as itself a suffering. The point I wish to address below through dwelling on Levinas's work on responsibility, guilt and susceptibility, is a matter not just of how we might feel a sense of reparation in light of the dynamics of aggression and love that plague us, but of how it is that I am, and do not merely feel, responsible for another in light of my guilt. In other words, how are students' utterances of guilt speaking about their own suffering? 


\section{RESPONSIBILITY, SUSCEPTIBILITY AND SUFFERING}

In Otherwise Than Being, Or Beyond Essence, Levinas (1998a) argues unequivocally that we are responsible for the other - inevitably and without question. And this is so because we are susceptible to the other, to the alterity that marks the other's life as infinitely unknowable. When we consider what this means in terms of the suffering of another, and in terms of the significance of guilt as a moral orientation, it is important to consider Levinas's conception of responsibility insofar as it does not reside in the full knowledge we can have of another's pain, even though we may know about such pain; it resides, instead, in the susceptibility we have to this suffering. Part of the dense landscape of responsibility in Levinas's work involves the subject being susceptible to the other to the point of guilt. It is this connection that I wish to explore here.

Levinas suggests that susceptibility is 'pre-originary' (Levinas, 1998a, p. 122), originating not in some empirical past (that would give the subject a psychical or developmental history, for instance), nor in some stable point in the past, but in a past that is wholly unrepresentable, and 'immemorial'. ${ }^{14}$ Guilt, in this view, lies in a strange relationship to time, for it continually emerges out of this unrepresentable and nonthematisable relation with the other and always gestures to the openness of the future. More importantly, susceptibility gives rise to responsibility because it inaugurates a relation in which the subject (or the I) is subjected to the other; that is, the I is always responsible for the other because it is in a relation of subjection - a relation, Levinas writes, of destitution, of persecution, of accusation. Levinas's depiction here is clear: the other commands the subject into being and in so doing initiates responsibility. Responsibility for the other is the very structure of subjectivity.

Part of one's susceptibility to another is an openness to the other's command; thus not only is susceptibility to the other a one-sided affair, whereby it is me and me alone who is commanded, but so too is responsibility. It is the self who is solely responsible, but always in relation to the other. In this regard, responsibility emanates from the other and thereby emerges through the very difference that structures human relationality. Levinas endeavours to posit this difference at the centre of responsibility and thus emphasises the uniqueness of the self's responsibility and its non-reciprocal nature. For Levinas, responsibility can only ever be borne by the self, the singular subject. Even as Levinas writes in the plural, it is the I, the self, the unique subject that is at stake in responsibility: 'In the responsibility we have for one another, $I$ have always one response more to give, I have to answer for his very responsibility' (Levinas, 1998a, p. 84, emphasis added).

In construing subjectivity as inevitably responsible, and construing this responsibility as coming from the other, Levinas's portrait of the self's encounter with the other takes on drastic and grave overtones. Insofar as 'I am obliged without this obligation having begun in me' (Levinas, 1998a, p. 13), the self is bound to the other in a relation of guilt 
in which the self bears the burden of the other's subjectivity, the other's freedom and the other's mortality. What responsibility and what guilt! How could one possibly avoid the stain of guilt in bearing this burden? Surely the self must be inadequate in the face of this monumental command?

Although references to guilt abound in his work, guilt is generally a complicated and little articulated notion for Levinas. Frequently quoting from Dostoevsky's The Brothers Karamazov, Levinas insists that 'Each of us is guilty before everyone for everyone, and I more than the others' (Levinas, 1998a, p. 146). ${ }^{15}$ Consistent with his emphasis, then, on the singular and unique nature of responsibility, Levinas invokes this quote repeatedly to indicate the enormous weight of responsibility. Yet, why does Levinas appeal specifically to guilt as a marker of responsibility?

It is not always made thoroughly clear, and the continual quoting from Dostoevsky acts in some way as a substitute for a more elaborated account of guilt. However, there are a number of key characteristics associated with guilt that are important for reflecting on declarations of guilt in the classroom. First, guilt emerges because it is almost as if responsibility - indeed subjectivity - demands too much of the self. The self is always in a state of subjection to the other, and therefore is always caught in the demand for the other's freedom. The self alone is guilty before the other because it can never fully provide for that freedom, since the other always faces a mortality the self cannot reverse. By this I mean that it is precisely because the self alone can only bear the other, rather than take it over, identify with it, consume it or console it, that the self is left inadequate to the task of responsibility commanded by the other: 'A face is ... given over to my responsibility, but to which I am wanting and faulty. It is as though I were responsible for his mortality, and guilty for surviving' (Levinas, 1998a, p. 91).

Yet another characteristic Levinas draws for us is the belatedness of response to this command from the other:

The neighbor assigns me before I designate him. This is a modality not of a knowing, but of an obsession, a shuddering of the human quite different from cognition ... In an approach I am first a servant of a neighbor, already late and guilty for being late. I am as it were ordered from the outside, traumatically commanded, without interiorizing by representation and concepts the authority that commands me (Levinas, 1998a, p. 87).

Thus the 'traumatic commandment' that always comes from the other cannot be assumed, understood or foreseen beforehand, nor can the command be theorised in terms of internalising the authority that the other represents (as, for instance, both Freud and Althusser postulate). That is, it is not a command that emerges from some authoritative position the other occupies. Instead, the command is prior to the law, the command comes from the other in an anticipatory state. The self's encounter with the other is of the nature of a surprise - unplanned, unthematised - thereby making all response to the other belated, after- 
the-fact, post-traumatic. In not being capable of the response that would fulfil the command, one can only be found guilty. As for Klein, guilt here emerges prior to any law or authority and is installed through the very susceptibility to another's presence.

But more important still is how guilt is invoked in Levinas's work in terms of the effect of this presence, of this commandment from the other. The trauma of encountering the other devolves into a persecution and a suffering, and this marks a third characteristic of guilt. ${ }^{16} \mathrm{We}$ are guilty because we are being accused by the other, are susceptible to this accusation, and suffer for it. The other's command (to which the only response for Levinas can be responsibility) is traumatic insofar as it calls me into question, and does so through my own suffering. ${ }^{17}$ For Levinas, to be guilty even in the face of such persecution - perhaps especially in the face of such persecution, where the suffering of the other and the possible death of the other pursues one fully and absolutely - is part of assuming responsibility not for one's own suffering but because of it. Our susceptibility to another means that we are guilty for deeds we have not committed; for guilt is not about deed or action, or about the content of the suffering of the other, but is a response to the trauma incurred through the other's telling of such suffering, what Levinas refers to as the 'saying' as opposed to the 'said'. ${ }^{18}$ In this way, one is persecuted by the speech act itself; in speaking her suffering, in addressing the self, the other inflicts a wound upon the self. The saying is a demand to be heard and it requires a response.

Within this responsibility - and only within this understanding of responsibility - guilt is seen to be a responsible response. The three elements of guilt discussed above - the inadequation of the self in responsibility, the belated response to the other, and the redoubling of suffering through the persecutory call of the other - all gesture toward the moral significance of guilt and the complex formations it takes with regard to one's exposure and susceptibility to another's pain. For this reason, Levinas's conception of guilt enables us to look beyond the self's motivations (both conscious and unconscious) in order to uncover - or posit - what it is that first must be in place in order for the subject to be responsive. Guilt does not ask 'What then is it to me? Where does he get his right to command? What have I done to be from the start in debt?' (Levinas, 1998a, p. 87). These questions reveal the ways in which the self reduces the other to the same, reduces the other to effects of the self, as if the only thing that mattered were how the other pertained to me. Alternatively, in decentring the self and in centring alterity, what Levinas emphasises is how guilt comes from the other. What guilt asks then is: What can I learn from the other? How might I respond to the other's command? What can I do for the other?

In learning from Levinas's own allusions to guilt, it may be that we are better able to navigate our way through the self-identifications of guilt that students make when confronted with knowledge about another's suffering. What Levinas theorises must be at stake in the susceptibility to the other is that one's response is formed in relation to the command of 
the other, not to the content of what another says. In this regard, student declarations of guilt say something about how they have responded to the other, how have they have learned from and not merely about the other - no matter what the teacher's intentions have been. That is, selfidentifying as guilty subjects, they inhabit positions that speak to all three characteristics of guilt mentioned above, revealing a nakedness and exposure in claiming their relation to the other. In terms of thinking about how the other persecutes the subject, declarations of guilt also speak to the very suffering that constitutes subjectivity. That is, selfidentifying as guilty signifies the suffering associated with listening to the other, the inescapable involvement students experience as they listen to stories of pain. Moreover, each of the positions sketched out at the beginning of this essay illustrates how listening brings with it its own traumatic repercussions.

What is evident in all three responses, for instance, is the very feeling of inadequacy in the face of another's suffering. Whether one declares such inadequacy outright ('I cannot do enough') or whether one declares inadequacy in terms of 'not having suffered enough', one articulates a struggle to figure out how one bears the weight of another's pain. Even in seeking to distance oneself from the other's pain (as is the case in the third instance), there is a tacit acknowledgement of the inadequacy of one's disposition in the face of such pain. That is to say, there is an inadequacy to the task of responding to the harm that has been done, and so one must retreat to a position of innocence. ${ }^{19}$ However, such declarations of guilt can be more or less tied to responsibility, depending on whether or not my self-identifying as guilty brings with it the capacity to ask 'how might I respond?' At times, this type of distancing is precisely a struggle with this question. How does one respond when one both is guilty and yet has not done anything wrong, when one is strangely innocent? At other times, it functions more (although not exclusively) to ward off any involvement of self with the other. It seems to me that this, then, is the pedagogical task set before us with regard to this kind of declaration. How do we engage students who struggle with their own place in engaging with difference as radical alterity?

All three positions reveal a structure of guilt in which students are awakening to the burden placed on them and to the necessity of shouldering that burden responsibly. The movement to self-identify as guilty may be read as a tentative movement from an initial susceptibility to the other toward assuming responsibility for the other. Yet, what must be emphasised here is that the links between susceptibility, guilt and responsibility cannot (and should not) be turned into a developmental process, one that follows a simple sequence of events: that is, one is susceptible to the other, one self-identifies as guilty and then one is on the royal road to responsibility. Instead, what I am suggesting here, following Levinas, is that one's approach to the other is just that, a movement toward another. Being able to theorise susceptibility, guilt and responsibility as movement helps us think through what it is students may be saying in their declarations - declarations which do 
not always follow the heuristic examples I have sketched above (human responses are, of course, rarely so neat). What Levinas's work leads to is a consideration of the way in which movement toward another is fundamentally a learning from the other. That is, my susceptibility to another's pain, my ability to suffer and be persecuted by the other, means that I have exposed myself to the other, that the other has entered me, has pierced the membrane of self-identity. That the other can transform us, can come at us from the outside, so that we can receive the other beyond the capacity of the I, to paraphrase Levinas, ${ }^{20}$ indicates to me that guilt is a response to learning itself.

\section{CONCLUDING THOUGHTS}

Considering guilt as having ethical weight offers possibilities for thinking through what it is we are attempting to do in introducing stories of suffering into our classrooms. I cannot stress enough that I do not view all expressions of guilt as occupying a privileged ethical site; yet I do think we need to concern ourselves with attending to the articulations of struggle that students reveal through their guilty selfidentifications. If our intent is to create possibilities for students to be moved by listening to stories of injustice, then we need to reflect carefully upon what such an encounter entails and to begin to understand where our responsibilities as educators lie. That is, when we count on students to be susceptible to those stories, then we also need to consider how such susceptibility is itself a condition of guilt and of responsibility. To simply dismiss guilt as a moral failing is, therefore, a grossly inadequate response, for guilt may be reflective of a kind of moral suffering on the part of students. Viewing guilt in this way, however, places a certain ethical demand on educators themselves.

What I do not want to suggest is that educators simply stop teaching sensitive material. Indeed, exposing students to portrayals of suffering seems an inevitable part of any educational project concerned with social justice. Nonetheless there are two issues that need to be mentioned. The first is an ethical question concerning how such material is given time in the class. Talking about reports of homeless people dying, for instance, can push some students to (almost) unbearable limits. Thus in thinking carefully about how to grapple with declarations of guilt in the classroom, there is first a need, I believe, to allow students opportunities for articulating their own complex responses (which can cut across a range of emotions, such as empathy and outrage as well as guilt). Whether this be done through various forms of discussion, essay writing or poetic expression, the point is to encourage students to see that their response inevitably implicates another. That is, no matter what the content of the response might be, it is the act of responding that places them in a potentially ethical relation with the people who are represented through stories of suffering. It is not that students ought to engage in endless navel-gazing, but that their responses of guilt, for instance, are 
seen to be morally significant for how one comes to take up a position of responsibility.

Second, there is a way in which guilty utterances produce their own 'saying', their own command to which teachers respond, in the same way that students respond to stories of injustice. Teachers, then, are themselves susceptible to the sufferings expressed through students' declarations of guilt. But to what exactly are teachers responding?

Klein's work makes it possible for us to consider such declarations as bound to a love that enables one both to feel badly for another's suffering and to reach out in a reparative gesture that seeks to ameliorate harm. In this way, the question for teachers becomes: how might I respond to guilt in a way that encourages students to think about its psychical complexity, that is, to see individual guilt as a relation the self has to another? In other words, how might an educator's response incorporate a sense of guilt that negates neither its possible moral significance nor the vicissitudes of affect that students bring to such declarations? On the other hand, Levinas's work allows for an understanding of guilt as a responsible response toward another's suffering at the same time as it creates suffering for the one who cannot help but be guilty. Teachers then are compelled to ask, how can my response to my students' suffering, refracted through their declarations of guilt, be itself responsible? To this end, there is a need to be open to and not judgemental about the guilt expressed by students. Such openness means attending to the saying of student declarations in such a way as to encourage more open dialogue about the place of affect in one's moral life.

What guilt so readily unveils are the difficulties of working across differences - those between students and stories of injustice, and those between teachers and students. This interminable work across differences, across the sufferings that wound us and bind us together in a guilty embrace, is what makes guilt so strange, so seemingly out of place in what we think ought to happen in the classroom. All too often we focus on what may be 'appropriate' content for teaching across difference, forgetting at times that we inhabit a space where difference is embodied, a space that as such is both wonderful and threatening, full of love and aggression. But what Levinas and Klein have taught us is that there is hope in learning from another. Perhaps we need to refocus what it is we think we do when we introduce stories of injustice in our classrooms and how it is we think we respond to students' guilty declarations. For if our students are suffering under the burden of an awakening responsibility for the other, and are struggling to work through their own love and aggression with regard to another's pain, then guilt needs to be heard - and indeed listened to.

\section{ACKNOWLEDGEMENTS}

Parts of this paper grew out of a presentation delivered at the Philosophy of Education Society's Annual Meeting in Toronto, 
March 2000. I wish to thank the reviewers for their thoughtful comments and Paul Standish for his keen editorial suggestions both have been enormously helpful.

\section{Correspondence: Sharon Todd, Faculty of Education, York University, 4700 Keele St., Toronto, Ontario M3J 1P3. \\ Email: stodd@edu.yorku.ca}

\section{NOTES}

1. See, for example, Leslie Roman, 1993, and Patricia Williams, 1991.

2. Levinas is consistent in his rejection of psychoanalysis. In a most basic sense, psychoanalysis as a theory that seeks to understand the subject necessarily conflicts with the Levinasian idea that understanding is not commensurable with ethical interaction. See note 13 for further elaboration.

3. A psychoanalytic view of remorse is distinguished from the remorse I am speaking of here. Freud is clear when he states that "when one has a sense of guilt after committing a misdeed, and because of it, the feeling should more properly be called remorse. It relates only to a deed that has been done, and, of course, it presupposes that a conscience - the readiness to feel guilty — was already in existence before the deed took place' (Freud, 1961, p. 131). This idea that remorse can only be felt for something one is directly involved in seems to me to underestimate the power of fantasy in thinking that we are fully responsible for deeds we consciously know not to have committed. Moreover, it is also the case that with regard to students talking about homelessness, for example, there is no singular deed or act for which people feel responsibility; what is at issue is rather a more generalised response to the ongoing forms of social contact students have with homeless people on the street.

4. See, for example, Roman's (1993) understanding of declarations of innocence as a form of white defensiveness.

5. Gabriele Taylor notes 'that the deed of another (my child, my compatriot) may make me feel shame but not guilt. Guilt itself cannot be vicarious' (Taylor, 1985, p.91). I am pushing the point here to acknowledge the fact that the guilt the self experiences necessarily implies a social relation.

6. Levinas makes reference to both other and Other, the former signalling a generalised other, the latter a specific person. I am confining my own usage here to other (except when quoting Levinas) in order to parallel the more general nature of students encountering others through biographies, films and narratives.

7. Clearly, we often dismiss these declarations of students in terms of 'liberal guilt'. For an alternative rendering, see Todd, 2000.

8. For a discussion of anxiety and learning, see Todd, 2001.

9. Klein writes: 'This making reparation is, in my view, a fundamental element in love and in all human relationships' (Klein, 1992, p. 312).

10. Freud identifies instincts, or more accurately, drives [Trieb] thus: 'an instinctual stimulus does not arise from the external world but from within the organism itself' and 'moreover, since it impinges not from without but from within the organism, no flight can avail against it' (Freud, 1954, p. 118). A drive is inescapable. Thus Klein's discussion of how reparation is set into motion seems slightly at odds with the inevitability that conventionally marks a drive. This lack of clarity over the specific dynamics involved in reparation speaks not only to a confusion on Klein's part, but is also, I think, symptomatic of the tenacity with which reparation is held onto by Klein as the only possible means for theorising our moral impulses.

11. Butler is acknowledging here, through a critical reading of Althusser, that the subject has guilt even before it knows it has access to the Law. In this sense her reading is rather Kleinian insofar as guilt exists prior to Oedipalisation and the internalisation of the Law it ushers in (Butler, 1997, p. 108).

12. See Ellison, 1996. 
13. In a passage from Otherwise Than Being, Or Beyond Essence Levinas is clear about the problem of understanding egos as unique while subjecting them to universalisable theories. One cannot help but think of psychoanalysis here: 'Obsession ... does not simply figure as a relation among all the reciprocal or at least reversible relations that form the system of the intelligibility of being, and in which the ego, even in its uniqueness, is a universal subsuming a multiplicity of unique egos' (Levinas, 1998a, p.83). Instead, Levinas proposes that such thematisation diminishes the ethical possibility of human relationality.

14. Levinas also connects this 'pre-originary' to the body and to maternity: 'Subjectivity as flesh and blood ... is the pre-original signifyingness that gives sense, because it gives. Not because, as pre-original, it would be more originary that the origin, but because the diachrony of sensibility, which cannot be assembled in a representational present, refers to an irrecuperable preontological past, that of maternity' (Levinas, 1998a, p. 78). While the whole subtext of the body and femininity cannot be addressed here, it is important to note that the pre-originary is precisely a non-beginning, what Levinas refers to as an-archy, that is necessary for sensemaking. In capturing this time in terms of maternity, there is a close affiliation in my view with Klein's emphasis on the signifyingness of the mother's body: for in Klein's work it is the maternal body which gives birth to symbolism and the possibility, therefore, of making sense.

15. Another translation of this appears in Levinas's works as: 'We are all guilty before everyone for everyone, and I more than all the others' (Levinas, 1998b, p. 105). However, the emphasis on 'each of us', rather than 'we', speaks more pointedly to the issue of singularity and uniqueness I am discussing here.

16. Although the scope of this paper prevents me from discussing this at length, the self also feels traumatised and persecuted because of the possibility of the other's death. Elisabeth Weber writes, 'the trauma of the encounter with the other is trauma of absolute responsibility, which is traumatic only because the one encountered can die' (Weber, 1995, p. 74). Levinas, moreover, is unequivocal in asserting that it is not only the possibility of one's death that is at stake, but the responsibility the I has towards the other's death: 'The proximity of the neighbour — the peace of proximity - is the responsibility of the $I$ for the other, the impossibility of leaving him alone before the mystery of death' (Levinas, 1999, p. 141). The theme of death and its relation to responsibility in Levinas's work is taken up more fully in Dennis Keenan King, 1999.

17. Simon Critchley offers a strong representation of what this trauma entails: "trauma is a "nonintentional affectivity", it tears into my subjectivity like an explosion, like a bomb that detonates without warning, like a bullet that hits me in the dark, fired from an unseen gun and by an unknown assailant' (Critchley, 1999, p. 236).

18. For Levinas, saying concerns the approach to the other that allows for signification, while the said refers to the content of what is spoken, or that which is signification. Thus the ethical relation lies within the saying of what is said.

19. I wish to emphasise again that this does not apply to those who 'blame' victims for their own misfortunes or who espouse hatred and prejudice toward selected groups. These reactions are not at all responsive nor responsible. Rather I am discussing those expressions of guilt/ innocence which articulate a genuine struggle to figure out one's own involvement in a harm committed. Moreover, they, like the other two declarations of guilt, must also be seen as a response to the teacher's pedagogical demand for students to take responsibility.

20. Levinas writes: 'It is therefore to receive from the Other beyond the capacity of the I, which means exactly: to have the idea of infinity. But this also means: to be taught' (Levinas, 1969, p. 51).

\section{REFERENCES}

Bauman, Z. (1993) Postmodern Ethics (Oxford, Blackwell).

Butler, J. (1997) The Psychic Life of Power: Theories in Subjection (Stanford, CA, Stanford University Press).

Critchley, S. (1999) The original traumatism: Levinas and psychoanalysis, in: R. Kearney and M. Dooley (eds), Questioning Ethics: Contemporary Debates in Philosophy (New York, Routledge).

Ellison, J. (1996) A short history of liberal guilt, Critical Inquiry, 22, pp. 344-371.

Freud, S. (1954) Instincts and Their Vicissitudes [1918], in: The Standard Edition of the Complete Psychological Works of Sigmund Freud, Vol. 14, trans. James Strachey (London, Hogarth Press). 


\section{S. Todd}

Freud, S. (1961) Civilization and Its Discontents [1930], in: The Standard Edition of the Complete Psychological Works of Sigmund Freud, Vol. 21, trans. James Strachey (London, Hogarth Press).

King, D. K. (1999) Death and Responsibility: The 'Work' of Levinas (Albany, NY, SUNY Press).

Klein, M. (1992) Love, Guilt and Reparation [1937], in: Love, Guilt and Reparation and Other Works 1921-1945, the Writings of Melanie Klein, Vol. 1 (London, Karnac Books).

Levinas, E. (1999) Peace and proximity, in: Alterity and Transcendence trans. Michael B. Smith (New York, Columbia University Press).

Levinas, E. (1998a) Otherwise Than Being or Beyond Essence, trans. Alphonso Lingis (Pittsburgh, Duquesne University Press).

Levinas, E. (1998b) Philosophy, justice, and love, in: Entre Nous: On Thinking-of-the-Other (New York, Columbia University Press).

Levinas, E. (1969) Totality and Infinity: An Essay on Exteriority, trans. Alphonso Lingis (Pittsburgh, Duquesne University Press).

O'Connor, N. (1991) Who suffers?, in: R. Bernasconi and S. Critchley (eds) Re-Reading Levinas (Bloomington, Indiana University Press).

Roman, L. (1993) White is a color! white defensiveness, postmodernism, and anti-racist pedagogy, in: Cameron McCarthy and Warren Crichlow (eds) Race, Identity, and Representation in Education (New York, Routledge).

Taylor, G. (1985) Pride, Shame and Guilt: Emotions of Self-Assessment (Oxford, Clarendon Press).

Todd, S. (2000) When is guilt more than just a petty face? Moving from liberal guilt toward reparation and responsibility in education, in: L. Stone (ed.) Philosophy of Education 2000 (Urbana, IL, Philosophy of Education Society).

Todd, S. (2001) 'Bringing more than I contain': ethics, curriculum, and the pedagogical demand for altered egos, Journal of Curriculum Studies, 33.4, pp. 431-450.

Weber, E. (1995) The notion of persecution in Levinas's Otherwise Than Being or Beyond Essence, in: A. Peperzak (ed.) Ethics as First Philosophy (New York, Routledge).

Williams, P. (1991) Gilded lilies and liberal guilt (reflections on law school pedagogy), in: The Alchemy of Race and Rights (Cambridge, Harvard University Press). 
Copyright of Journal of Philosophy of Education is the property of Blackwell Publishing Limited and its content may not be copied or emailed to multiple sites or posted to a listserv without the copyright holder's express written permission. However, users may print, download, or email articles for individual use. 